\title{
Understanding Tourism at Heritage Religious Sites
}

\author{
Daniel Levi and Sara Kocher
}

Daniel Levi, PhD. is a professor at the Psychology and Child Development Department, Cal Poly. Sara Kocher, Ph.D. is an environmental planning consultant in San Luis Obispo.

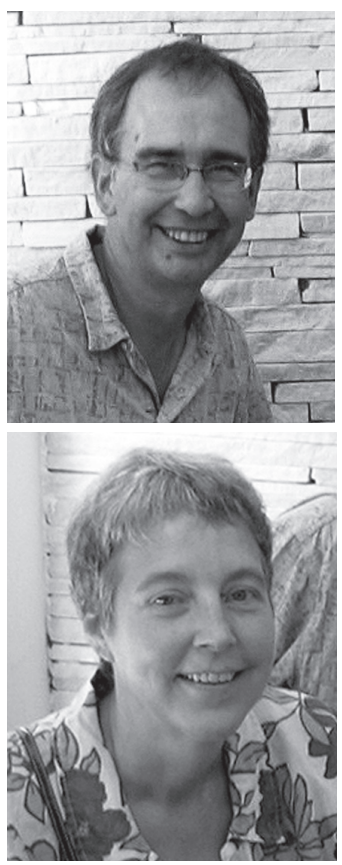

Figure 1 Chiang Mai Wat Temple, Thailand.
Based on their recent international comparative research project, the authors discuss the relationship between tourism and religious sites that are considered historical and architectural heritage. Using sites in California and Thailand in their study they show how authentic experiences of sacred places and the spiritual culture of a region can promote sustainable tourism and benefit both the tourist and the community.

Cultural heritage tourism is an important part of the international tourist market. As with any resource, sustainable management practices are required to maintain the long-term value of cultural heritage assets. Sustainable tourism provides quality experiences for the tourists while protecting the environment and improving the quality of life for local residents (Moscardo, 1998). Planning for sustainable tourism requires balancing the requirements of cultural heritage preservation, tourists, and the local community.

Cultural heritage assets include both tangible assets, such as historic places, and intangible assets, such as cultural practices (McKercher \& du Cros, 2002). These assets are preserved because of their intrinsic value to the community, rather than for their tourist value (Charoenwongsa, 2004). Tourism creates a dilemma for the organizations that manage cultural heritage assets. Tourism provides a powerful political and economic justification for site conservation; however, inappropriate use, increased visitation, and commercialization are threats to the integrity of the site.

Tourists visit cultural heritage sites for a variety of reasons (Ho \& McKercher, 2006). They vary from the purposeful tourist who is seeking authentic cultural experiences to the casual tourist who may be visiting a historic site simply because it is part of their tour. The cultural significance of a site is often more important to the local community than to tourists. When an area contains a large number of cultural heritage attractions, tourists tend to visit only the most popular sites.

Cultural heritage tourism has both positive and negative impacts on the local community (UNEP, 2002). Tourism can be a significant part of a local economy, create business and employment opportunities, and thereby encourage support for the preservation of cultural heritage assets. However, tourism costs the host community because of the need for infrastructure development to support the tourist

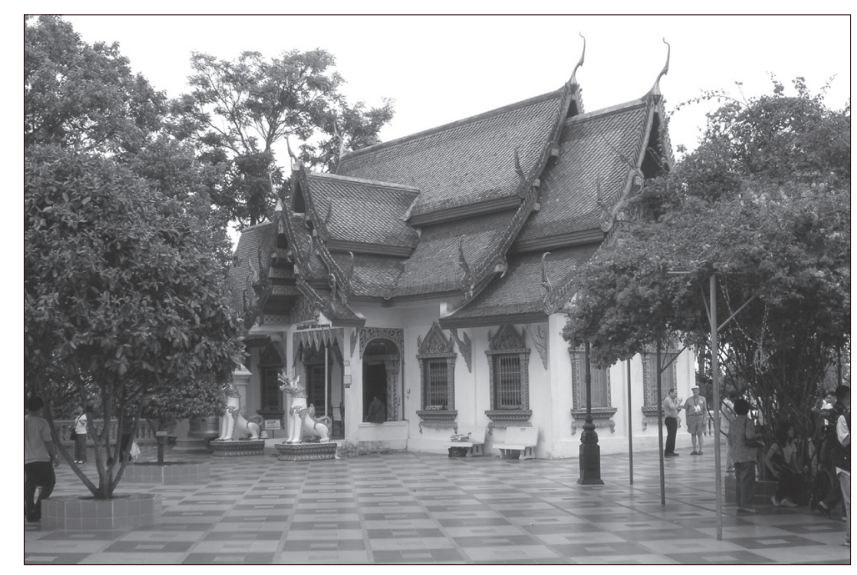
industry. Tourist related commercialization may degrade the environment near heritage sites. Increased use causes wear and deterioration of heritage sites, thereby increasing the cost of maintenance. Appropriate management of cultural sites and the tourist industry can reduce some of these negative impacts and encourage support for tourism by the local community.

Tourism at religious or sacred sites is a special type of cultural heritage tourism (Shackley, 2001). Preserving cultural heritage at religious sites requires allowing the local community to continue using the site; however, religious practices can be disrupted by the presence of tourists. Inappropriate tourist activities and commercial development around a heritage religious site can lead to the trivialization of the site (McKercher \& du Cros, 2002). Many 
heritage religious sites encourage donations to help compensate for the impacts of tourism, but donations rarely cover the cost of maintenance and preservation (Olsen, 2006).

Preservation of a heritage religious site and its continued use is an important component in the sustainability of cultural values (McKercher $\&$ du Cros, 2002). The local community and worshipers have a mixed relationship with the tourists who visit there (Bremer, 2004). Residents often take pride in their culture and religion and want to share their enthusiasm with outsiders. However, tourists disrupt religious practices and increase maintenance problems.

Tourists often view visits to historic religious sites as opportunities for cultural and educational experiences (Olsen, 2006). They are seeking authentic experiences that are tied to a specific historic place, rather than just leisure in a resort that could be anywhere (Macleod, 2006). Interpretation can be used to help provide these experiences, while reducing some of the negative impacts of tourism (Coccossis, 2005). Interpretation can help the tourists better appreciate what they are seeing; reduce congestion and crowding by making tourists aware of alternative sites to visit; and explain appropriate tourist behaviors that minimize impacts on the site and its religious use.

When heritage religious sites and practices are commercialized and changed for easy tourist consumption, the site often looses its authenticity (McKercher \& du Cros, 2002). The level of commercialization at the sites to accommodate tourism often conflicts with visitor expectations about what is appropriate at a religious place (Nolan \& Nolan, 1992). But management of sites without considering the tourist experience leads to dissatisfaction and lack of support for cultural historic preservation.

\section{RESEARCH PROJECT}

Our research examined heritage religious sites in California and Thailand from the perspective of the tourists. The methods we used included analysis of existing tourism studies, site visits, behavioral observations, and visitor surveys. The research sites included the Catholic Missions of Central California and the Buddhist Wats (temples) of Chiang Mai, Thailand. In both regions, tourism is a major industry, with cultural tourism an important part of the tourist market. The main historic sites are religious buildings, which are used both as places of worship by the local community and tourist attractions.

Figure 2

Mission Santa Barbara, California.
The 21 California Missions were built by Spanish Catholic missionaries from 1769 to 1823 (Sunset, 1979). With the exception of two that are state parks, the Missions are owned by the Catholic Church and most conduct regular religious services. They are the most visited historic sites in California and are part of grade school education in the State. The Chiang Mai region of Northern Thailand has over 60 historic Wats, with the earliest Wats constructed in the 14th century (Freeman, 2001). The Buddhist church owns all of the Wats. Most of them have residences for monks and are used for religious, educational, and community services.

To fund the maintenance and preservation of the Missions, the Catholic Church relies on contributions from church members,

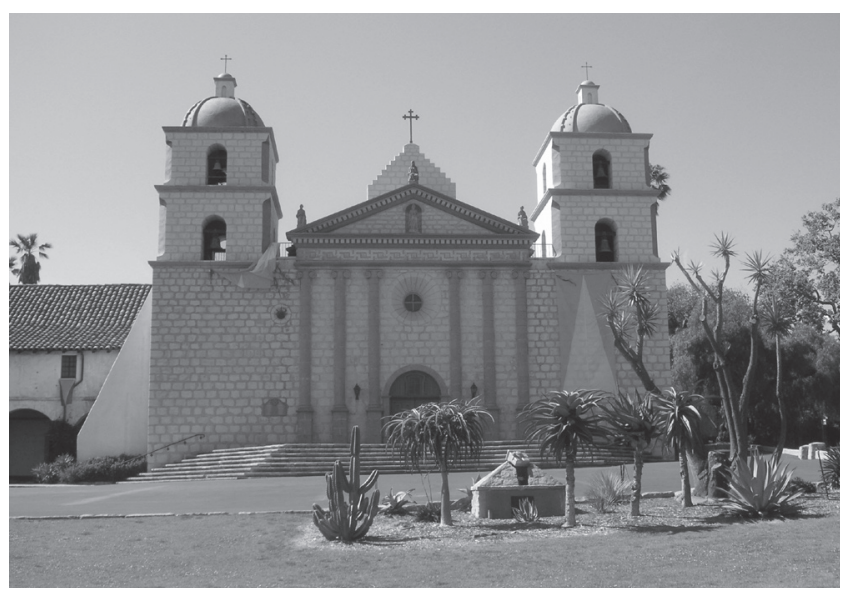




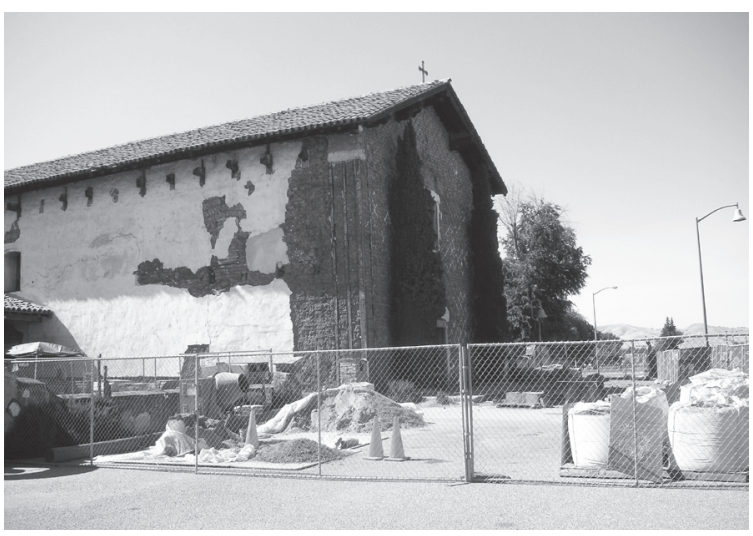

Figure 3

Repairs at San Miguel Mission, California. tourists, and non-profit organizations (Bremer, 2000). Missions in urban and tourist areas are better equipped to raise preservation funds from the public. In Thailand, funds from church members, tourists, private non-profits, and the government help to preserve the historic Wats. Even though tourism is a major industry in Chiang Mai, the large number of Wats means that only a few of them have a substantial number of tourist visitors (Chifos, 2006).

The historic Wats and Missions are hybrid environments that are both religious and tourist places. At many of the Missions, there are attempts to separate the church services from the tourist activities (Bremer, 2000). Interpretation for the tourists at the Missions focuses on the Mission's role in the history and culture of California. At the Thai Wats, there are few attempts to separate religious activities from tourism. Many of the tourists are Thais who want to participate in religious activities as part of their tourism (Peleggi, 1996). Interpretation at the Wats focuses on presenting the Buddhist religion to visitors, including international tourists, to participate in religious practices.

\section{RESULTS AND IMPLICATIONS}

We found more similarities than differences in the experience of Missions and Wats. In general, the Wats were rated higher than the Missions on overall visitor experience, religious experience, and opportunities for education and participation.

In both types of environments, the perception of these places as being authentic and religious was a positive attribute for the visitors. Experiencing these historic religious sites as sacred places that are used by the local community was an important part of the tourist experience. When the site became crowded or commercialized for tourism, the perceived spirituality of the place was reduced and the tourist experience suffered.

These results have several important implications for the management of heritage religious sites. Whenever possible, religious use of the sites by the local community should be encouraged. Continued use of heritage religious sites is important for both the tourists and local community.

Figure 4 Religious use by the local community provides meaning to the site and supports preservation and

Mission in San Luis Obispo, California.

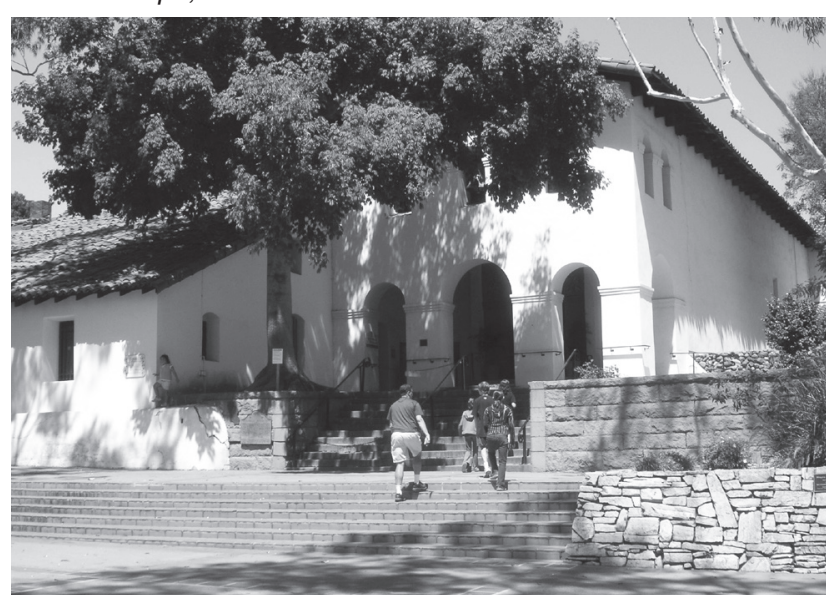

the tourist's personal and cultural experience.

From a design perspective, there are three main challenges created by tourism at these heritage religious sites: inappropriate tourist behaviors, overcrowding, and commercialization. The sheer numbers of tourists at heritage sites causes physical and social impacts. When there are too many tourists, these places loose their sense of spirituality; they shift from being sacred to secular places.

Inappropriate tourist behaviors can be controlled in several ways. At the Missions, tourists are often not allowed in chapel areas during services to reduce conflicts, but this also limits opportunities for participation and education and may reduce the experience of the Missions as a religious site. In contrast, tourists and worshippers are less likely to be segregated at the Buddhist 
Wats. At the frequently visited Wats, it is a common practice to have guides and monks available to answer questions, and areas available for tourists who wish to engage in worship oriented activities. On the other hand, the Missions are more likely to provide written materials and signage with guidelines for visitor behavior. Both Missions and Wats could benefit from incorporating the techniques used by their religious counterparts to encourage appropriate tourist behaviors.

A common approach to reduce overcrowding is for the sites to charge fees to discourage the casual tourist; however, fees can be viewed as inappropriate at religious sites and may create access problems for the local community. In Thailand, one popular Buddhist Wat has a foreigner entrance fee; a practice that is highly resented by international tourists. Some California Missions charge fees to enter

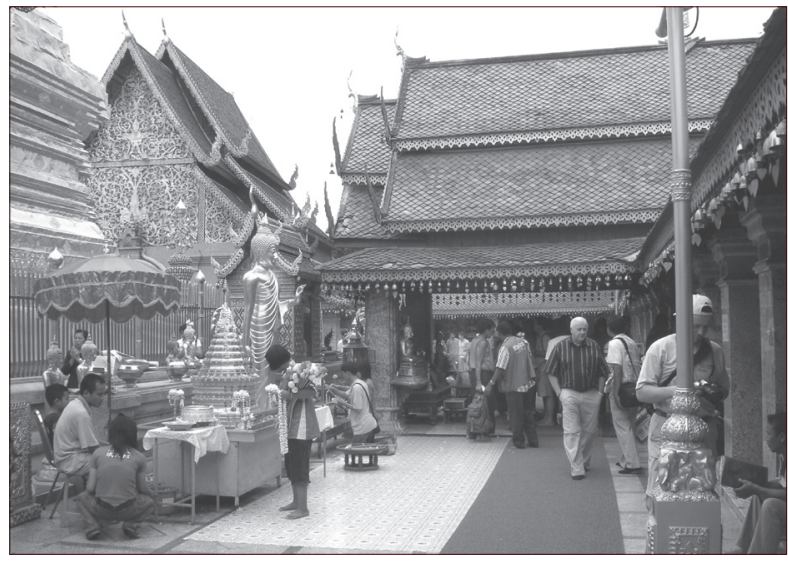
their museums and to tour the site, while access to religious services is free, but rigorously controlled. At some sites in both countries, there are places that are considered so sacred or fragile that tourists are not allowed to visit. Tourism can also be limited to certain times to reduce conflicts with local worshippers.

Interpretive materials can also be used to reduce overcrowding by identifying the unique characteristics of less popular sites deserving of tourist visitation. For instance, the rural Missions are more likely to have preserved gardens and grounds characteristic of the settlement period, while the less visited Wats are more likely to incorporate folk art and provide intimate environments for worship reflective of the surrounding neighborhoods. Most tourists visit only the most popular heritage religious site in a region, and as a consequence, these sites are well funded, while less popular sites lack funds for preservation and maintenance. Interpretive materials identifying a wider range of religious sites and the opportunities available could encourage tourists to visit alternative Missions and Wats and help alleviate the issues associated with overcrowding and underfunding.

Although tourists seek authentic experiences, commercialization occurs because the tourist industry tries to make the sites more comfortable for visitors by standardizing the tourist experience. Religious practices may be modified and shortened so that tourists do not lose interest. Gift shops, food, and other tourist commodities and services may be sold at the heritage site and in adjacent areas. Tourists have a mixed view of this commercialization, but often see it as incompatible with the religious experience of cultural heritage sites.

The tourists visiting these sites are most troubled by tourist oriented commercial development located immediately adjacent to the entrance, both inside and outside the site complex. At many of the Missions, visitors enter through the gift shop, an introduction to the site that creates an impression of commercialization that persists throughout the visit. Centuries of design theory recognize the impact of the entry on overall perception of landscape and architectural monuments, and these non-expert evaluators were sensitive to it as well. Minimizing commercial development at the entrance to the site by creating a buffered entry corridor would help preserve the impression of historic and cultural integrity.

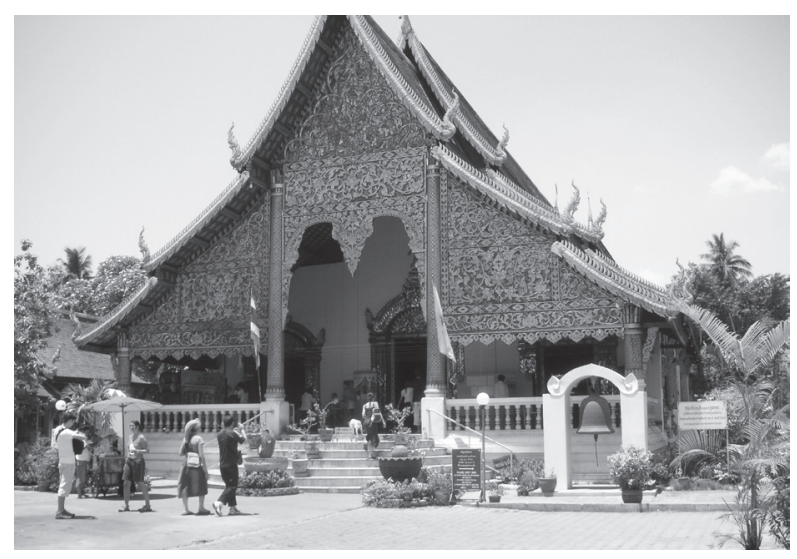

Figure 5

Tourists and worshippers at Chiang Mai Wat, Thailand.
Figure 6

Tourists at Chiang Mai Wat Temple, Thailand. 
The nature of the goods and services offered also makes a difference to visitors. At the Wats, visitors are often pleased that vendors offer cold drinks, while gift shops and kiosks offer a preponderance of generic tourist items with no relation to the site are thought to be a distraction. Gift shops at the Missions are filled with a variety of tourist souvenirsand are viewed as less appropriate than shops with primarily historic or religious items.

Tourists are looking for opportunities to experience cultural heritage sites. Providing opportunities for authentic experiences of sacred places and the spiritual culture of a region promotes sustainable tourism that benefits both the tourist and the community.

\section{REFERENCES}

Bremer, T. 2000. Tourists and religion at Temple Square and Mission San Juan Capistrano. The Journal of American Folklore, 113(450), 422-435.

Bremer, T. 2004. Blessed with tourists: The borderlands of religion and tourism in San Antonio. Chapel Hill: University of North Carolina Press.

Charoenwongsa, P. 2004. Heritage resource management in tourism. In M. Bradford \& E. Lee (Eds.), Tourism and cultural heritage in Southeast Asia (pp. 41-53). Bangkok: SEAMEO-SPAFA.

Chifos, C. 2006. Culture, environment and livelihood: Potential for crafting sustainable communities in Chiang Mai. International Journal of Environment and Sustainable Development, 5(3), 315-332.

Coccossis, H. 2005. Operational management of cultural and heritage sites. In M. Sigala \& D. Leslie (eds.) International cultural tourism: Management, implications and cases (pp 53-64). Amsterdam: Elsevier.

Freeman, M. 2001. A guide to Northern Thailand and the ancient kingdom of Lanna. Trumbull, CT: Weatherhill Inc.

Ho, P. \& McKercher, B. 2004. Managing heritage resources as tourism products. Asia Pacific Journal of Tourism Research, 9(3), 255-266.

Macleod, N. 2006. Cultural tourism: Aspects of authenticity and commodification. In M. Smith \& M. Robinson (eds.) Cultural tourism in a changing world (pp. 177-190). Clevedon: Channel View Publication.

McKercher, B. \& du Cros, H. 2002. Cultural tourism: The partnership between tourism and cultural heritage management. New York: Haworth Hospitality Press.

Moscardo, G. 1998. Interpretation and sustainable tourism: Functions, examples and principles. Journal of Tourism Studies, 9(1), 2-13.

Nolan, M. \& Nolan, S. 1992. Religious sites as tourism attractions in Europe. Annals of Tourism Research, $19,68-78$.

Olsen, D. 2006. Management issues for religious heritage attractions. In D. Timothy \& D. Olsen (Eds.) Tourism, religion and spiritual journeys (pp 104-118)). New York: Routledge.

Peleggi, M. 1996. National heritage and global tourism in Thailand. Annals of Tourism Research, 23(2), 432-448.

Shackley, M. 2001. Managing sacred sites. Padstow, UK: Thomson.

Sunset (editors) 1979. The California Missions: A pictorial history. Menlo Park CA: Sunset Books.

UNEP. 2002. Sustainable tourism. Retrieved at www.uneptie.org/pc/tourism. 